\title{
Postoperative Immobilization following Occipitocervical Fusion in the Pediatric Population: Outcome Evaluation and Review of Literature
}

\author{
Alexandre R. Pingarilho ${ }^{c}$ Paulo M. Porto de Melo ${ }^{c}$ Samer K. Elbabaaa,b \\ a Division of Pediatric Neurosurgery, Department of Neurological Surgery, Saint Louis University School of Medicine, \\ Saint Louis, MO, and bediatric Neurosurgery, Pediatric Neuroscience Center of Excellence, Arnold Palmer Hospital \\ for Children, Orlando, FL, USA; ${ }^{C}$ Departamento de Neurocirurgia. Hospital Militar de Área de São Paulo - HMASP, \\ Exército Brasileiro, São Paulo, Brazil
}

\section{Keywords}

Occipitocervical fusion · Children · Postoperative

immobilization · Literature review

\begin{abstract}
The scientific literature does not have a consensus about the role and method of postoperative immobilization after occipitocervical fusion in the pediatric population. The primary goal of this study is to review the medical literature and evaluate different immobilization methods and their impact on fusion, following the surgical management of craniocervical instability in children. It started with an extensive research of randomized controlled trials, series of cases and case reports, describing occipitocervical junction pathologies, clinical, epidemiological characteristics, and treatment. The search was performed using the Pubmed database evaluating all the literature involving postoperative immobilization after occipitocervical fusion in pediatric patients. The results showed that most cases of occipitocervical stabilization were due to congenital spinal instability followed by trauma in most series. The most common type of surgery performed was occipitocervical fusion using screw and rod constructs.
\end{abstract}

The different methods of postoperative immobilization did not affect outcomes. Then, we can conclude that screw-androd constructions in occipitocervical fusion augment the rates of fusion, independently from which immobilization was used, even when none was used at all.

(C) 2018 S. Karger AG, Base

\section{Introduction}

The occipitocervical junction comprises 2 important joints for head and neck movements and stability: the atlanto-occipital and atlantoaxial joints. The involved bones include the occipital bone $(\mathrm{O})$, atlas $\left(\mathrm{C}_{1}\right)$ and axis $\left(\mathrm{C}_{2}\right)$.

This region is considered as the site of a wide variety of pathologies. They can be divided into congenital, developmental, and acquired. In this context, traumatic/ posttraumatic, congenital, and inflammatory conditions (rheumatoid arthritis), neoplasms, and infections (Grisel syndrome) stand out. Any of these, if not treated, can lead to severe neurological impairments.

Congenital abnormalities are common to find at birth and in early childhood. Most of them are syndromes,

\section{KARGER}

(c) 2018 S. Karger AG, Basel 
Table 1. Demographic data

\begin{tabular}{lllrrc}
\hline Authors & Year & $n$ & Males & Females & Age \\
\hline Teodore et al. [19] & 2016 & 40 & 20 & 20 & 7.3 years $(5.2-9)$ \\
Ruiz-Picazo Díez-Ulloa [4] & 2014 & 2 & 1 & 1 & $4-8$ years \\
Takeshima et al. [17, 18] & 2014 & 1 & 0 & 1 & 18 years \\
Ramos [20] & 2013 & 3 (1 excluded - no surgery required) & 0 & 2 & $10-12$ years \\
Fulkerson et al. [5] (1) & 2012 & 31 & 17 & 14 & 8.3 years \\
Fulkerson et al. [5] (2) & 2012 & 2 & 0 & 2 & $18-21$ months \\
Wang [21] & 2011 & 1 & 1 & 0 & 18 years \\
Bauman et al. [8] & 2011 & 12 & 5 & 7 & 13 years (1.5-18 years) \\
Brockmeyer [22] & 2011 & 1 & 0 & 1 & 14 years \\
Mobbs [23] & 2010 & 1 & 1 & 0 & 14 years \\
Weng et al. [1] & 2010 & 1 & 0 & 1 & 13 years \\
Bisson et al. [10] & 2010 & 1 & 0 & 1 & 16 years \\
Plant and Ruff [16] & 2010 & 1 & 1 & 0 & 13 years \\
Dhellemmes [24] & 2008 & 28 (only 6 surgically treated) & 3 & 3 & 6.5 years (0.5 months to 16 years) \\
Glaser et al. [13] & 1986 & 23 & 16 & 7 & 11.5 years (5-18 years) \\
Lowry et al. [14] & 1997 & 25 & 11 & 14 & 9 years (3-15 years) \\
\hline
\end{tabular}

such as Chiari malformations, Klippel-Feil, Down, and Morquio syndromes. Some nonsyndromic abnormalities, simply congenital malformations, such as congenital atlantoaxial dislocation and occipitalization of the atlas, can also be encountered [1-4].

These pathologies generate 4 types of anomalies: (1) basilar impression/invagination; (2) atlanto-occipital dislocation; (3) atlantoaxial dislocation; (4) occipitalization of the atlas or thin posterior arch of atlas, which may cause compression of the cervical spinal cord. When unstable and symptomatic, they need to be approached surgically, aiming at decompression and fusion. Most common traumatic indications include motor vehicle accidents, sport-related injuries, falls, child abuse, and others $[5,6]$.

Considering the level of injury in the cervical spine, occipitocervical and atlantoaxial $\left(\mathrm{O}-\mathrm{C}_{1}-\mathrm{C}_{2}\right)$ are the most affected levels, followed by subaxial cervical spinal levels $\left(\mathrm{C}_{3}-\mathrm{C}_{7}\right)$. The treatment of these conditions may include conservative management or surgical management via a posterior approach for decompression and fusion [6].

To promote occipitocervical fusion, many techniques were developed and improved over time, which includes wiring and use of autografts (rib graft), allografts, arthrodesis using screw/rods and use of bone morphogenetic protein; the goal is to promote a successful fusion. Following surgery, many methods of craniocervical immobilization can be used to increase occipitocervical fusion rates; however, which one achieves the highest rates, with lowest complications, remains unknown $[7,8]$.

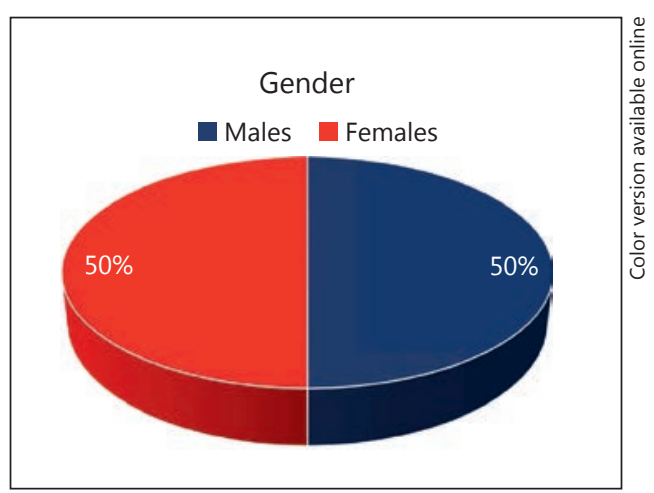

Fig. 1. Subjects' gender.

\section{Materials and Methods}

The literature review involved clinical case reports, randomized controlled trials, series of cases, describing occipitocervical junctional pathologies, clinical, epidemiological characteristics, and treatments. The search was performed using the Pubmed database targeting all English language publications available involving postoperative immobilization after occipitocervical fusion in patients under the age of 18 years. This review was organized applying the MeSH terms formula $(\mathrm{A})+(\mathrm{B})+(\mathrm{C})$, where the plus symbol means AND: (A) using advanced search builder engine $\left(\mathrm{Pubmed}^{\odot}\right)$ : spine OR cervical spine OR cervical OR occipital OR craniovertebral junction OR craniocervical junction pathologies OR upper cervical spine pathologies OR cervical spine abnormalities OR cervical spine malformation OR occipitocervical congenital disorders OR developmental conditions of the cervical spine OR craniocervical junction abnormalities OR traumatic injuries of the craniocervical junction OR traumatic injuries of 
Table 2. Etiology of occipitocervical instability

\begin{tabular}{|c|c|c|c|c|c|c|c|c|c|c|}
\hline Authors & Year & $n$ & Trauma & $\begin{array}{l}\text { Con- } \\
\text { genital }\end{array}$ & $\begin{array}{l}\text { Inflam- } \\
\text { matory }\end{array}$ & $\begin{array}{l}\text { Neo- } \\
\text { plasms }\end{array}$ & Vascular & $\begin{array}{l}\text { Hardware } \\
\text { failure }\end{array}$ & Infections & $\begin{array}{l}\text { Multiple } \\
\text { causes }\end{array}$ \\
\hline Teodore et al. [19] & 2016 & 40 & 18 & 15 & 1 & 1 & 1 & 3 & & 1 \\
\hline Takeshima et al. $[17,18]$ & 2014 & 1 & 0 & 0 & 0 & 0 & 1 & 0 & 0 & 0 \\
\hline Ramos [20] & 2013 & 3 & 0 & 0 & 2 & 0 & 0 & 0 & 0 & 0 \\
\hline Fulkerson et al. [5] 1 & 2012 & 31 & 8 & 17 & 3 & 3 & & & & \\
\hline Wang [21] & 2011 & 1 & 0 & 1 & 0 & 0 & 0 & 0 & 0 & 0 \\
\hline Bauman et al. [8] & 2011 & 12 & 3 & 6 & 0 & 1 & 0 & 2 & 0 & 0 \\
\hline Brockmeyer [22] & 2011 & 1 & 0 & 1 & 0 & & & & & \\
\hline Mobbs [23] & 2010 & 1 & 0 & 1 & 0 & 0 & 0 & 0 & 0 & 0 \\
\hline Weng et al. [1] & 2010 & 1 & 0 & 0 & 0 & 0 & 0 & 0 & 0 & 1 \\
\hline Bisson et al. [10] & 2010 & 1 & 1 & 0 & 0 & 0 & 0 & 0 & 0 & 0 \\
\hline
\end{tabular}

Fig. 2. Etiology of occipitocervical instabil-

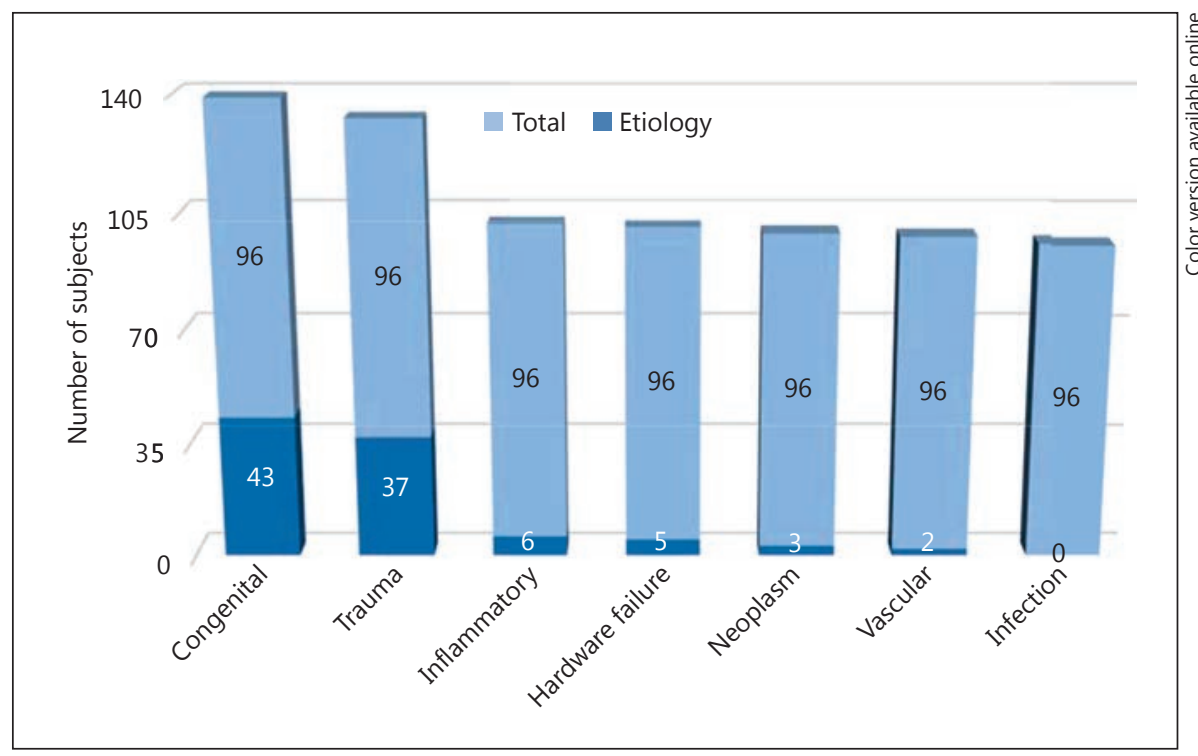
ity.

the cervical spine OR children cervical spine injury; (B) spinal instrumentation OR occipitocervical fusion OR screw OR fixation OR fusion OR posterior cervical fusion OR craniovertebral fusion OR posterior instrumentation OR postoperative immobilization after occipitocervical fusion OR postoperative immobilization after craniocervical intervention OR immobilization of the cervical spine in children OR conservative management of cervical spine injuries OR immobilization after occipitocervical instrumentation OR immobilization OR cervical orthotic devices OR orthotic devices OR halo vest OR halo OR cervical collar; (C) randomized controlled trials OR case reports OR literature review. The search in Pubmed/Medline retrieved 54,466 articles. For all these articles, we applied filters such as species (humans) and age (pediatric group: birth to 18 years old). Then, we retrieved 632 papers. Analyzing article titles, 156 were selected for summary review, considering relevance and relation to this paper. From these 156 articles, 16 were selected and examined, considering related content to this paper objective. All relevant data were collected and tabulated in a Microsoft Excel ${ }^{\complement}$ table. All articles eligible for this study were case reports and literature reviews. Here, we describe the characteristics of the management of occipitocervical fusion, its etiologies, and outcomes. 
Table 3. Procedure characteristics

\begin{tabular}{|c|c|c|c|c|c|c|}
\hline Author & Year & $n$ & Fixation and fusion & Levels, $n$ & Immobilization & Rate of fusion \\
\hline Teodore et al. [19] & 2016 & 40 & Pin with sublaminar wiring & 5 & Miami I collar & $100 \%$ \\
\hline Ruiz-Picazo Díez-Ulloa [4] & 2014 & 2 & Occipitocervical fusion with rods and screws & 1 & None & $100 \%$ \\
\hline Takeshima et al. $[17,18]$ & 2014 & 1 & Atlantoaxial posterior fixation with iliac bone graft & 1 & Firm neck brace & $100 \%$ \\
\hline Ramos [20] & 2013 & 3 & Occipitocervical fusion with rods and screws & 1 & Minerva jacket & $100 \%$ \\
\hline Fulkerson et al. [5] 1 & 2012 & 31 & Occipitocervical fusion with rods and screws & $\begin{array}{l}\text { Not } \\
\text { mentioned }\end{array}$ & None & $94.40 \%$ \\
\hline Fulkerson et al. [5] 2 & 2012 & 2 & Posterior lateral mass screws with bone matrix protein & 1 & Hard cervical collar & $100 \%$ \\
\hline Wang [21] & 2011 & 1 & $\mathrm{C}_{1}$ hook, $\mathrm{C}_{2}$ pedicle screws, and iliac autografts & 1 & Hard cervical collar & $100 \%$ \\
\hline Bauman et al. [8] & 2011 & 12 & Occipitocervical fusion with rods and screws & 3 & Halo vest ( 4 cases) & $100 \%$ \\
\hline Brockmeyer [22] & 2011 & 1 & Lateral mass with screws (iliac crest graft) & 1 & None & $\begin{array}{l}84.3 \% \text { (after first } \\
\text { procedure) }\end{array}$ \\
\hline Mobbs [23] & 2010 & 1 & Pedicle screws & 2 & Cervical orthesis & $100 \%$ \\
\hline Weng et al. [1] & 2010 & 1 & Occipitocervical fusion with rods and screws & 2 & Halo vest (before surgery) & $100 \%$ \\
\hline Bisson et al. [10] & 2010 & 1 & Occipitocervical fusion with rods and screws & 3 & $\begin{array}{l}\text { Halo vest (before and } \\
\text { after surgery) }\end{array}$ & $100 \%$ \\
\hline Plant and Ruff [16] & 2010 & 1 & Lateral mass with screws (iliac crest graft) & 1 & None & $100 \%$ \\
\hline Dhellemmes [24] & 2008 & 6 & Atlantoaxial posterior fixation with iliac bone graft & 2 & None & $100 \%$ \\
\hline Glaser et al. [13] & 1986 & 3 & $\begin{array}{l}\text { Wedge compression arthrodeses of } \mathrm{C}_{1} \text { and } \mathrm{C}_{2} \text { by the } \\
\text { Brooks technique }\end{array}$ & 2 & Halo vest & $100 \%$ \\
\hline Glaser et al. [13] & 1986 & 20 & $\begin{array}{l}\text { Interspinous fusions of the lower cervical spine with internal } \\
\text { fixation consisting of a cerclage wire inserted in a modified } \\
\text { Rogers fashion for ligamentous instability }\end{array}$ & 2 & Halo vest & $100 \%$ \\
\hline Lowry et al. [14] & 1997 & 25 & 17 (Brooks technic), 8 (sublaminar wires) & $\begin{array}{l}6 \text { (two levels) } 19 \\
\text { (1 level) }\end{array}$ & Halo vest & $84 \%$ \\
\hline
\end{tabular}

Table 4. Neurological status

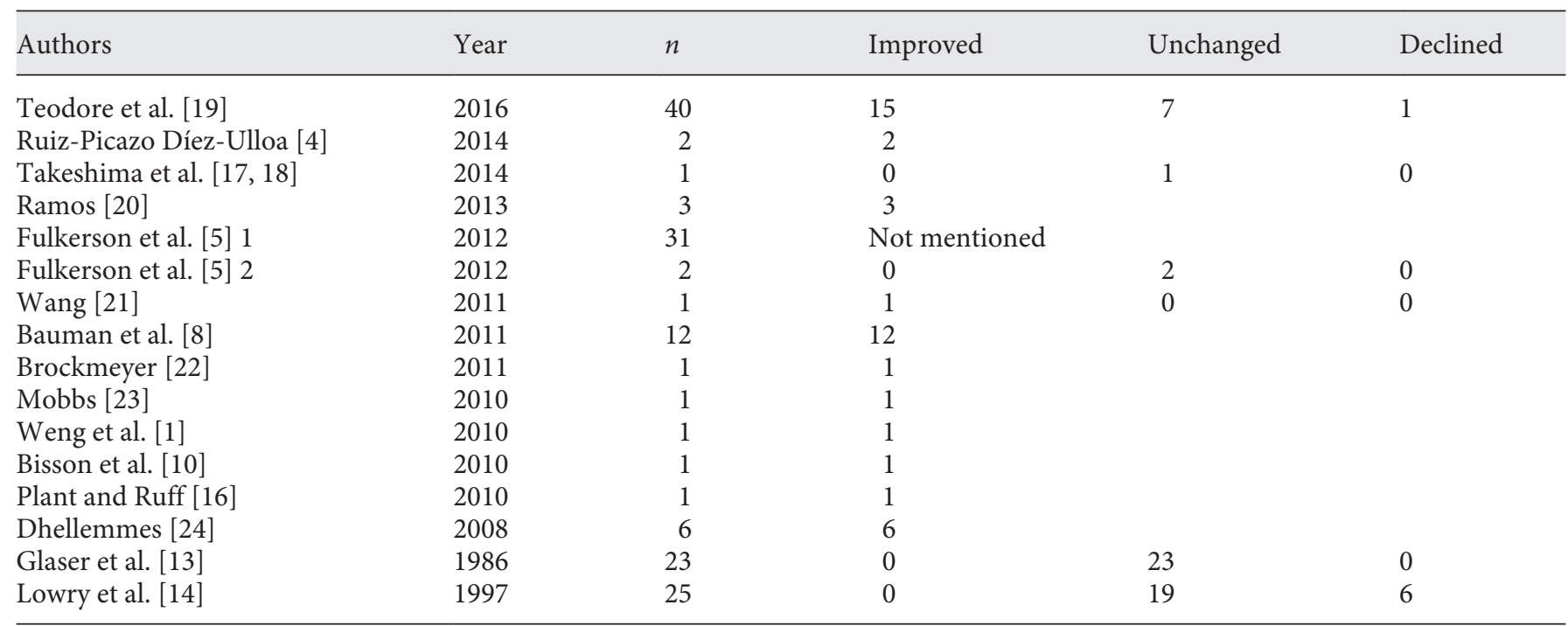

\section{Results}

The total of subjects analyzed in 14 articles were 173, but 7 were excluded as a result of nonsurgical treatment. 83 were males and 83 females with a mean age of 11.4 years, ranging from 15 days of life to 18 years old (Fig. 1; Table 1).

According to etiologies of occipitocervical instability, 85 were due to trauma, 43 due to congenital malforma- tions, 6 inflammatory, 5 hardware failures, 3 neoplasms, 2 vascular, and none caused by infection. Most of the traumas that caused occipitocervical instability had a subjacent condition of congenital malformations (Fig. 2; Table 2).

The most common technique observed in the literature was occipitocervical decompression, fusion, and instrumentation using screws and rods. However, other surgical techniques such as pin with sublaminar wiring, 
Table 5. Surgical complications

\begin{tabular}{|c|c|c|c|c|c|c|c|}
\hline Authors & Year & $n$ & $\begin{array}{l}\text { Wound } \\
\text { problems }\end{array}$ & $\begin{array}{l}\text { Vertebral } \\
\text { artery injury }\end{array}$ & Hardware failure & $\begin{array}{l}\text { Pneumo- } \\
\text { thorax }\end{array}$ & Dysphagia \\
\hline Teodore et al. [19] & 2016 & 40 & 2 & 1 & & 1 & 0 \\
\hline Takeshima et al. $[17,18]$ & 2014 & 1 & 0 & 0 & 0 & 0 & 0 \\
\hline Ramos [20] & 2013 & 3 & & & & & \\
\hline Wang [21] & 2011 & 1 & 0 & 0 & 0 & 0 & 0 \\
\hline Bauman et al. [8] & 2011 & 12 & 0 & 0 & 0 & 0 & 0 \\
\hline Brockmeyer [22] & 2011 & 1 & 0 & 0 & 0 & 0 & 0 \\
\hline Mobbs [23] & 2010 & 1 & 0 & 0 & 0 & 0 & 0 \\
\hline Weng et al. [1] & 2010 & 1 & 0 & 0 & 0 & 0 & 0 \\
\hline Bisson et al. [10] & 2010 & 1 & 0 & 0 & 0 & 0 & 0 \\
\hline Lowry et al. [14] & 1997 & 25 & 6 & 0 & 1 & 0 & 0 \\
\hline
\end{tabular}

atlantoaxial posterior fixation with iliac bone graft, posterior lateral mass screws using bone matrix protein, $\mathrm{C}_{1}$ hook/ $C_{2}$ pedicle screws using iliac autografts, and lateral mass with screws using iliac crest graft were described too. Older data demonstrate wiring/allograft construct preference or simply availability due to technology limitation (Table 3).

Considering the number of levels involved in the occipitocervical fusion constructs, we found a mean value of 1.84 and a range from 1 to $6 ; 1$ article has not mentioned the number of levels approached for the fusion constructs. All studies reported $100 \%$ of fusion, after the first procedure, except 2 that had approximately $84 \%$ of fusion rate (Table 3 ).

Considering postoperative immobilization, they described a variety of methods including soft collars, hard collars, Minerva jacket cast to halo vest. The choice of immobilizations was based on the individual characteristics, anatomy, and personal experience of the professionals more than any evidence-based or scientifically proven method or protocol (Table 3; Fig. 3).

With older constructs as wiring technics, the halo vest was preferably used for stabilization and augmentation of fusion. When we consider screw-and-rod constructs, there is no consensus for postoperative immobilization, which is often not used (Table 3).

Among all the subjects, 44 had neurological improvement. 52 had no neurological change compared to admis- sion and only 7 declined neurologically. It demonstrates that these procedures are safe and efficient (Table 4).

Regarding surgical complications, $4.48 \%$ developed wound problems (pin infection), 1 patient had a vertebral artery injury, 2 patients had hardware failure (pin loosening and loss of alignment), and 1 patient had pneumothorax. Neurological improvement was reported in 66 subjects. The postoperative neurological status remained unchanged in 11 patients, and only 1 had worsening of the preoperative neurological condition (Table 5).

\section{Discussion}

Upon reviewing the medical literature, we found that the most frequent cause of occipitocervical instability and consequent need for fusion was cervical spine trauma. Yet, congenital malformations were very frequent, and in some series represent the most common cause of craniocervical fusion. The abnormalities found were spinal anomalies (29.1\%), Chiari malformation (19.7\%), trauma (17.3\%), Down syndrome (16.5\%), skeletal dysplasia (14.2\%), and os odontoideum $(3.1 \%)[9,10]$.

The choice of fusion constructs depends on many factors, including individual characteristics, subjacent disease, occiput bone density, involvement of posterior cervical elements, surgeon expertise, and technology avail- 

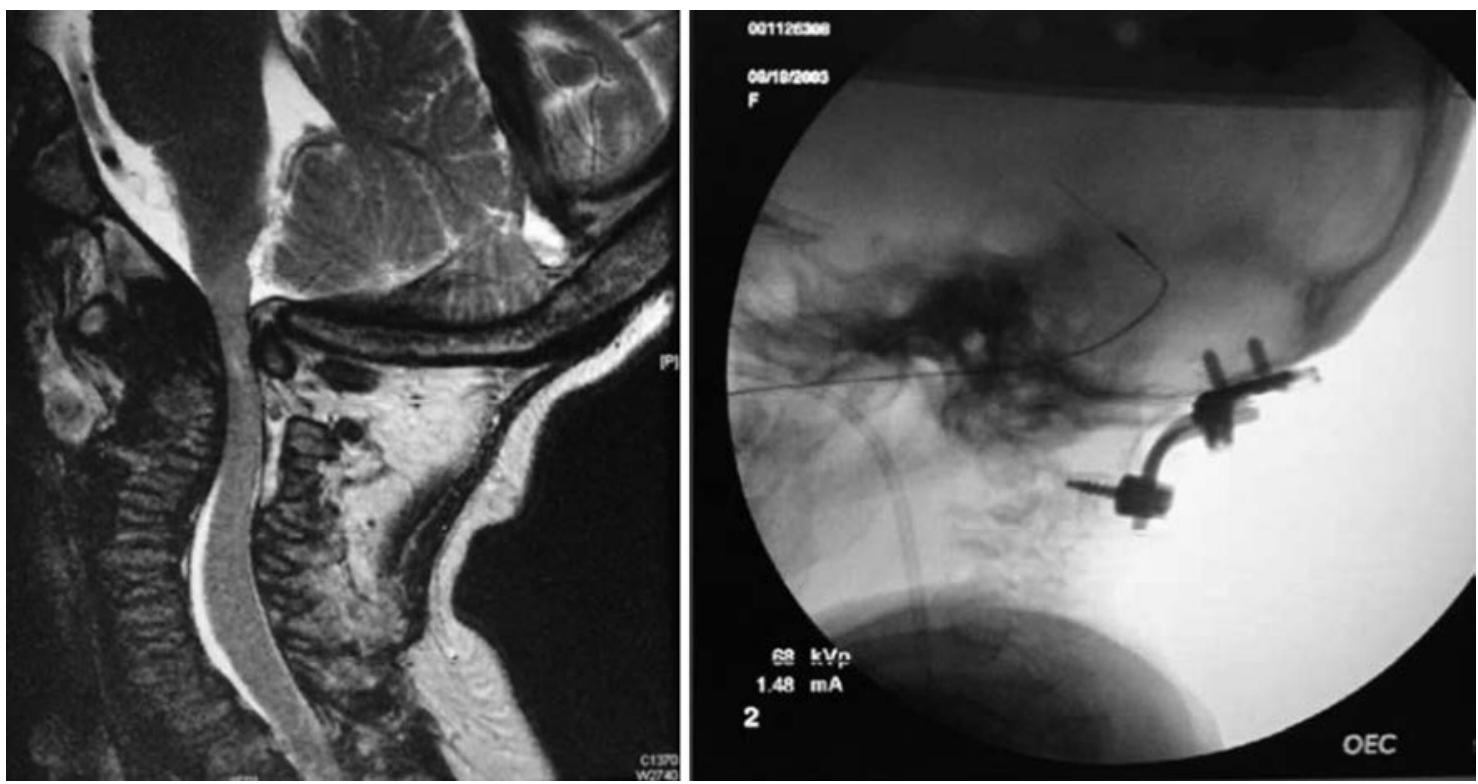

Fig. 3. Ten-year-old child with Morquio syndrome and craniocervical instability treated with occiput- $\mathrm{C}_{2}$ instrumentation and rib graft treated with halo for 3 months.
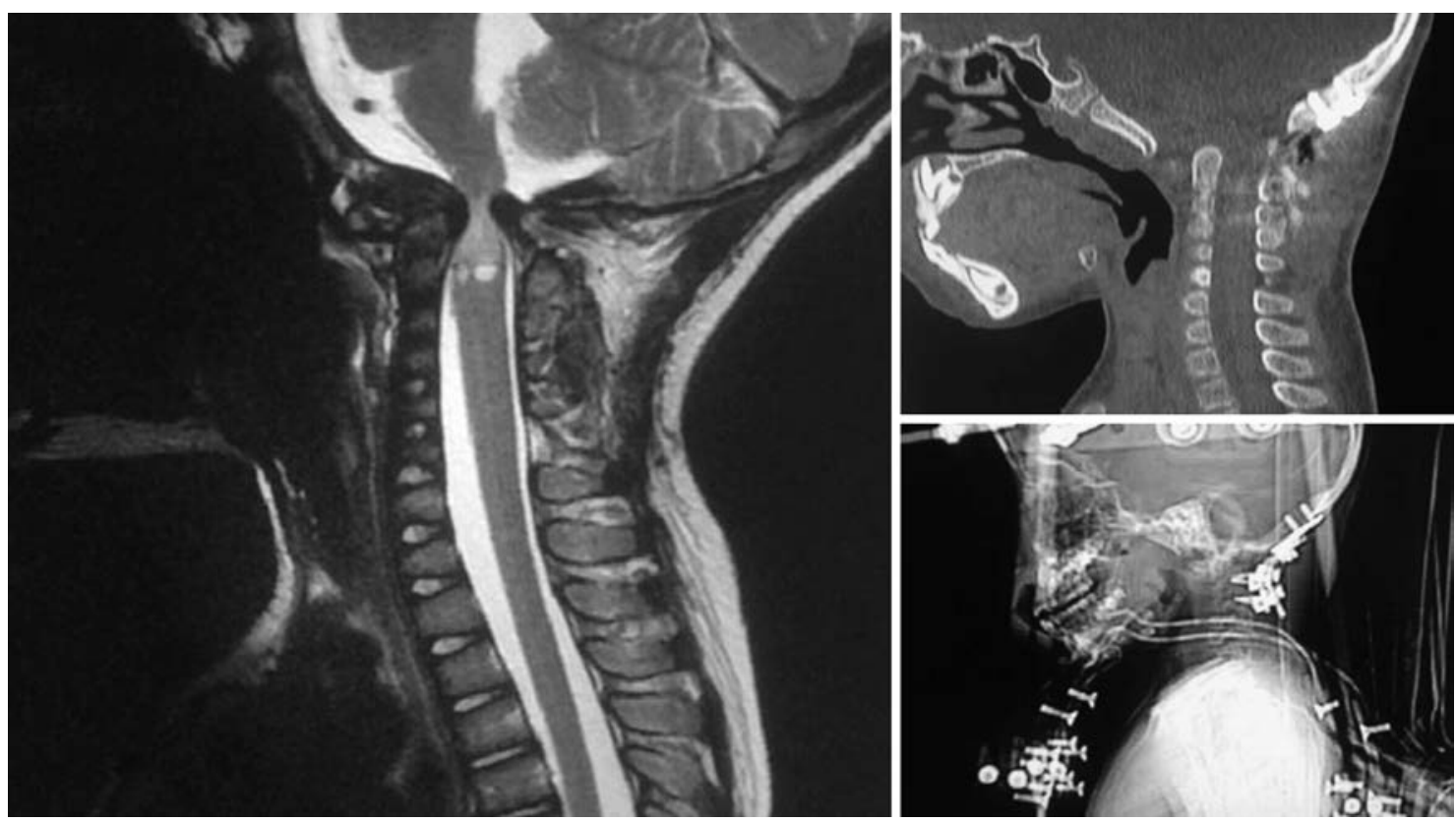

Fig. 4. Three-year-old child with myelopathy and congenital atlantoaxial and atlanto-occipital instability treated with decompression and occiput- $\mathrm{C}_{3}$ instrumentation and rib graft treated with halo for 3 months.

ability. It has been proved that screw-and-rod constructs achieve better results regarding stability and safety [11].

Regarding choice of fusion constructs, during time, 2 basic types of construct are available: wiring/grafts and screw/rod constructs. Wiring and use of auto/allografts constructs represent a very well-accepted method when children did not have adequate bone thickness for screw purchase, but it is a less stable option to promote spinal fusion. To optimize fusion rates, authors indicated postoperative immobilization use of a halo vest [12-14] (Fig. 4). 
Screw-and-rod constructs, when available and indicated, represent a safe and very stable method of fusion, dispensing the need of immobilization. Regarding technology advances, with low bone thickness of cervical spine vertebras of smaller children, it is not an issue; new materials are available for use in these cases, promoting a safe and stable method of fusion [14].

In a series of 107 cases, fusion procedures were performed on children of $7.7 \pm 4.7$ years of age (mean), ranging from 1.2 to 17.9 years. In this series, $59.1 \%$ (63) were male patients, and 40.9 (44) were female. 127 occipitocervical fusion procedures were reported. Among them, 107 patients $(84.3 \%)$ achieved complete fusion after the first procedure, 20 (15.7\%) failed and needed reoperation [9].

It is already well established that motion of the craniocervical junction must be restricted for a successful fusion $[11,15]$.

Immobilization is considered in some selected nonoperative cases and comprises different types of orthesis, including hard or soft cervical collars, cervicothoracic orthosis, and others. The choice is made based on the type of injury or condition, patient comorbidities, and the center's experience. Postoperative immobilization after occipitocervical fusion follows the same criteria [6].

Complications described in the literature and related to pedicle screws and rod constructs were nonfusion, screw loosening, infection, persistent pain, and CSF fistulas $[11,16]$.

Vertebral artery damage is the worst and most feared complication in a craniocervical fusion construct and may lead to severe morbidity and death. Rates of vertebral artery injury range from $1.3 \%$ (2/149 patients) to $4.1 \%$ $(54 / 1318$ patients) $[11,17,18]$.

\section{Limitations}

The present study reveals the lack of high-level evidence studies as systematic reviews and randomized controlled trials about this issue. Case reports and personal experience prevail in the literature, leading to high-level rates of bias. This demonstrates that management of occipitocervical diseases in children still does not have a consensus. The lack of well-designed, prospective, and multicenter studies markedly limits the establishment of any practice recommendations or practice guideline from this paper.

\section{Conclusion}

Occipitocervical fusion constructs determine whether postoperative immobilization is needed or not. Once the technic of fusion has been chosen, the type of postoperative immobilization did not affect the rate of fusion, but the complications that develop within the method. Older constructs using wiring and grafts are less stable than screw-and-rod constructs and, apparently, need some orthesis for cervical immobilization. Screw-and-rods constructs represent a very stable method for promoting cervical fusion and, regarding specific cases, do not need postoperative immobilization.

\section{Disclosure Statement}

There is no conflict of interest.

\section{References}

1 Weng C, Wang L, Wang W, Tan H: Bipartite atlas with os odontoideum and synovial cyst. Spine 2010;35:E568-E575.

2 Chau A, Wong J, Mobbs R: Cervical myelopathy associated with congenital $\mathrm{C}_{2 / 3}$ canal stenosis and deficiencies of the posterior arch of the atlas and laminae of the axis. Spine 2009; 34:E886-E891.

3 Klimo P, Coon V, Brockmeyer D: Incidental os odontoideum: current management strategies. Neurosurg Focus 2011;31:E10.

4 Ruiz-Picazo Díez-Ulloa M: Occipital-cervical instability in Morquio disease: a presentation of two cases and a review of the literature. Rev Esp Cir Ortop Traumatol (Engl Ed) 2014;58: 387-394.
5 Fulkerson D, Hwang S, Patel A, Jea A: Open reduction and internal fixation for angulated, unstable odontoid synchondrosis fractures in children: a safe alternative to halo fixation? J Neurosurg Pediatrics 2012;9:35-41.

6 Duhem R, Tonnelle V, Vinchon M, Assaker R, Dhellemmes P: Unstable upper pediatric cervical spine injuries: report of 28 cases and review of the literature. Child Nerv Syst 2007; 24:343-348.

7 Hwang S, Gressot L, Rangel-Castilla L, Whitehead W, Curry D, Bollo R, et al: Outcomes of instrumented fusion in the pediatric cervical spine. J Neurosurg Spine 2012;17:397-409.
8 Bauman J, Hardesty D, Heuer G, Storm P: Use of occipital bone graft in pediatric posterior cervical fusion: an alternative paramedian technique and review of the literature. J Neurosurg Pediatrics 2011;7:475-481.

9 Mazur M, Sivakumar W, Riva-Cambrin J, Jones J, Brockmeyer D: Avoiding early complications and reoperation during occipitocervical fusion in pediatric patients. J Neurosurg Pediatrics 2014;14:465-475.

10 Bisson E, Schiffern A, Daubs M, Brodke D, Patel A: Combined occipital-cervical and atlantoaxial disassociation without neurologic injury. Spine 2010;35:E316-E321.

11 Lall R, Patel N, Resnick D: A review of complications associated with craniocervical fusion surgery. Neurosurgery 2010;67:1396-1403. 
12 Li X, Jiang W, Yang H, Tang T, Gong X, Yuan J, et al: Surgical treatment of chronic $\mathrm{C}_{1}-\mathrm{C}_{2}$ dislocation with absence of odontoid process using $\mathrm{C}_{1}$ hooks with $\mathrm{C}_{2}$ pedicle screws. Spine 2011;36:E1245-E1249.

13 Glaser JA, Whitehill R, Stamp WG, Jane JA: Complications associated with the halo-vest. J Neurosurg 1986;65:762-769.

14 Lowry DW, Pollack IF, Clyde B, Albright AL, Adelson PD: Upper cervical spine fusion in the pediatric population. J Neurosurg 1997; 87:671-676.

15 Mazur M, Ravindra V, Brockmeyer D: Unilateral fixation for treatment of occipitocervical instability in children with congenital vertebral anomalies of the craniocervical junction. Neurosurg Focus 2015;38:E9.

16 Plant J, Ruff S: Migration of rod through skull, into brain following $\mathrm{C} 1-\mathrm{C} 2$ instrumental fusion for os odontoideum. Spine 2010;35:E90E92.
17 Takeshima Y, Nishimura F, Park Y, Nakase H: Fusion surgery for recurrent cerebellar infarctions due to bilateral atlantoaxial rotational vertebral artery occlusion. Spine 2014; 39:E860-E863.

18 Takeshima Y, Nishimura F, Park Y, Nakase H Fusion surgery for recurrent cerebellar infarctions due to bilateral atlantoaxial rotational vertebral artery occlusion. Spine 2014; 39:E860-E863.

19 Martinez-del-Campo E, Turner JD, RangelCastilla L, Soriano-Baron H, Kalb S, Theodore N: Pediatric occipitocervical fixation: radiographic criteria, surgical technique and clinical outcomes based on experience of a single surgeon. J Neurosurg Pediatr 2016;18: 452-462.

20 Ortiz GL, Pratts I, Ramos E: Grisel's syndrome: an unusual cause of Torticollis. J Pediatr Rehab Med 2013;6:175-180.
21 Li XF, Jiang WM, Yang HL, Tang TS, Gong $\mathrm{XH}$, Yuan J, Wang G: Surgical treatment of chronic C1-C2 dislocation with absence of odontoid process using $\mathrm{C} 1$ hooks with $\mathrm{C} 2$ pedicle screws: a case report and review of literature. Spine 2011;36:E1245-E1249.

22 Klimo P Jr, Coon V, Brockmeyer D: Incidental os odontoideum: current management strategies. Neurosurg Focus 2011;31:E10.

23 Chau AM, Wong JH, Mobbs RJ: Cervical myelopathy associated with congenital $\mathrm{C} 2 / 3 \mathrm{ca}$ nal stenosis and deficiencies of the posterior arch of the atlas and laminae of the axis: case report and review of the literature. Spine 2009;34:E886 -E891.

24 Duhem R, Tonnelle V, Vinchon M, Assaker $\mathrm{R}$, Dhellemmes P: Unstable upper pediatric cervical spine injuries: report of 28 cases and review of the literature. Childs Nerv Syst 2008; 24:343-348. 